\title{
Does Corporate Governance Matter for Market Efficiency? Evidence from Turkish Markets
}

\author{
Dina Cakmur Yildirtan, $\mathrm{PhD}$ \\ Marmara University, School of Banking, Capital Markets Dept., Istanbul, Turkey \\ Tel: 90-216-414-9989Ｅ-mail: dinacakmur@yahoo.com.tr
}

Alper Ozun, $\mathrm{PhD}$ (Corresponding author)

Turkiye Is Bankas1, Treasury Department, Istanbul, Turkey

Tel: 90-212-316-1211Ｅ-mail: Alper.Ozun@isbank.com.tr

\begin{abstract}
This article examines informational efficiency in the Corporate Governance Index comprising of firms having corporate governance ratings in Turkish equity markets. By using ARFIMA FIGARCH model, it is empirically showed that Corporate Governance Index does not display long-memory effect, thus is in weak-form efficiency. The article has originality in that it examines Corporate Governance Index in Turkey in terms of market efficiency by employing ARFIMA-FIGARCH model that consider coexistence of long-term memory in return and volatility.
\end{abstract}

Keywords: Corporate governance, Market efficiency, Long-memory models, Turkish equity markets

JEL codes: G32, G14, C14 


\section{Motivation and Literature Review}

In this empirical paper, we examine if having a corporate governance rating has an effect on informational efficiency in stock returns. We provide first evidence from Turkish equity markets with a long-term memory model. Most of the empirical work on the subject cumulates on developed markets.

In Turkey, a stock market index called Corporate Governance Index was created on 29th August 2007. It includes market capitalization of firms having corporate governance rating above from 6 over 10. The rating is given by specialized firms authorized by Capital Markets Board of Turkey. Currently, there are 24 companies within the Index.

We try to empirically show that the CGI is in weak-form efficiency by analyzing if it has long-term memory. As a methodology, we choose ARFIMA-FIGARCH model to cover long-memory effect in both mean (return) and volatility (risk). We provide evidence for the benchmark index for the market which is ISE-100 Index. As much as we know, it is the first empirical research examining the efficiency of CGI in Turkey.

Volatility in stock returns is important for trading and risk management functions. Volatility in returns occurs due to time dependent market information. Therefore, transparency in information flow is crucial for emergence of volatility in stock returns. For that reason, on the practical side, corporate governance; on the methodological side, Autoregressive Conditional Heteroskedastic $(\mathrm{ARCH})$ models are main pillars of studies focusing on market efficiency.

$\mathrm{ARCH}$ models in that the variance of the dependent variable is modeled as a function of past values of the dependent variable or exogenous variables. ARCH models, which are used to forecast conditional variances, are constructed by Engle (1982) and generalized as GARCH (Generalized ARCH) by Bollerslev (1986) and Taylor (1986).

Alternative GARCH models are used to estimate the return volatility in financial instruments. EGARCH (Nelson, 1991), GJR-GARCH (Glosten, Jagannathan and Runkle; 1993), IGARCH (Engle and Bollerslev; 1986), FIGARCH (Baillie et al., 1996; Chung, 1999), FIEGARCH (Bollerslev and Mikkelsen, 1996), FIAPARCH (Tse, 1998) and HYGARCH (Davidson, 2001) are the well-known extensions of the ARCH model. The empirical evidence shows that GARCH models can provide good in-sample parameter estimates and, when the appropriate volatility measure is used, reliable out-of-sample volatility forecasts.

On the other hand, long memory and fractionary Brownian motion as a concept are originally discussed by Hurst (1951) and Mandelbrot (1963). However, these concepts are applied for discrete time-series by Granger (1980), Granger and Joyeux (1980), and Hosking (1981). Long-memory process in financial time series analysis is extended by Baillie et al., (1996) and Chung (1999). The empirical studies show that FIGARCH model is suitable for detecting long-memory in financial time series in emerging economies (Cifter and Ozun, 2007).

In terms of effects of corporate governance on market efficiency is controversial. Early arguments defend that corporate governance protect management from dismissal, may not be beneficial to shareholders. Those kinds of arrangements can lead to emergence agency costs 
and, create a reduction in shareholder wealth Easterbrook and Fischel (1981). On the other hand, recent empirical evidence displays the fact that having a corporate governance rules is helpful to have informational efficiency in stock returns. Recent evidence in favour of a positive relationship between market efficiency and good corporate governance is provided by John and Senbet (1998), Hermalin and Weisbach (2003), Gompers et.al. (2003), and Karathanassis and Drakos (2004).

In Turkish markets, the relationship between having corporate governance and market efficiency has not examined, yet. We have witnessed an empirical paper using ARFIMA-FIGARCH model to examine long-memory in stock returns at the ISE-100 Index. Kasman and Torun (2007) investigates the dual long memory in the Turkish stock market by testing memory for the returns and volatility with daily data from 1988 to 2007 . They show that long memory in the returns and volatility can be modelled by using the ARFIMA-FIGARCH model. In other words, they find out strong evidence of long memory in both returns and volatility. They conclude that stock prices follow a predictable behaviour, and therefore, the market is not efficient.

In the next part, we present data with unit root tests and descriptive statistics. In the third part, ARFIMA-FIGARCH model and its implications for market efficiency is explained. In the fourth part, empirical evidence and test results are discussed in terms of theoretical and practical policy implications. The paper ends with suggestions for future research and conclusion.

\section{Data}

In empirical tests, data set is composed by using daily returns of the Corporate Governance Index (CGI) and Istanbul Stock National 100 Index (ISE-100 Index) from 31.08.2007 to 26.01.2010 including 595 observations. Data starts from 31.08.2007 since the CGI was firstly calculated on that time. The closing prices of the indexes are received from Bloomberg Plc.

The return series is adjusted by taking logarithmic difference as $r_{t}=\ln \left(P_{t} / P_{t-1}\right) * 100$, where $\mathrm{r}$ is daily return and $\mathrm{P}$ is closing value of index.

Figure 1 and Figure 2 show logarithmic returns of CGI and ISE-100 Index, respectively for sample period. We can clearly follow volatility clustering in the indexes in the Figures.

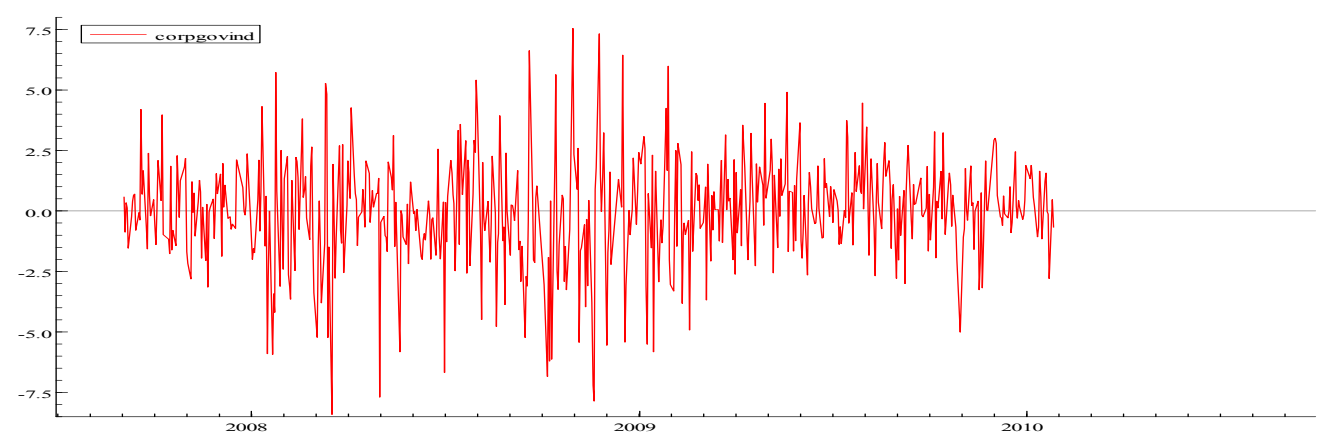

Figure 1. Corporate Governance Index Return Series 


\section{Il Macrothink}

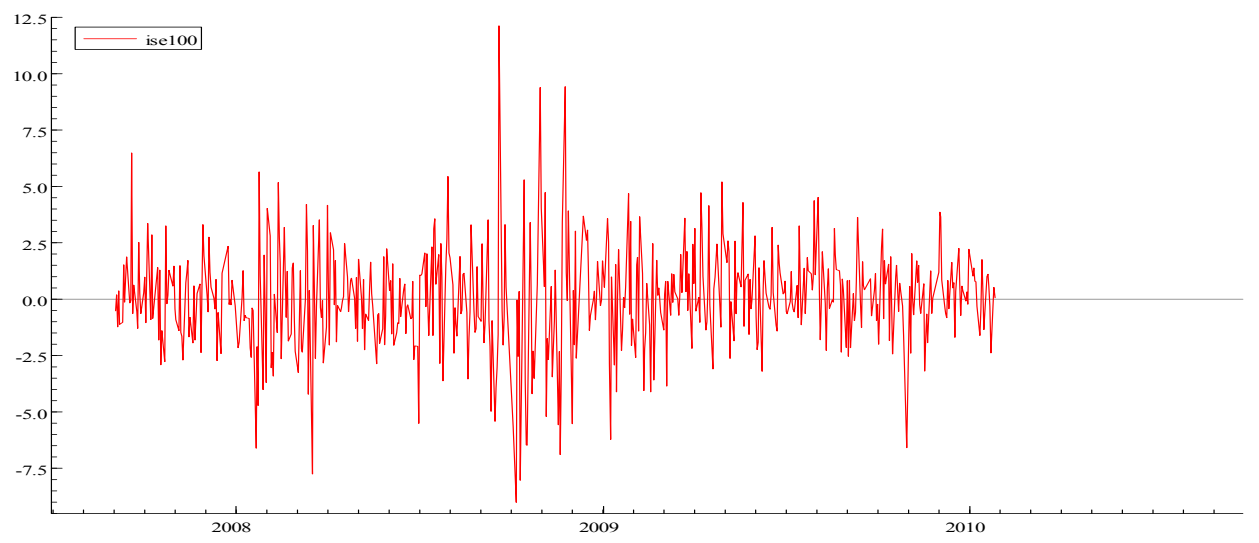

Figure 2. ISE-100 Index Return Series

The descriptive statistics for CGI and ISE-100 Index are summarized in Table 1.

Table 1. Summary Statistics

\begin{tabular}{|l|l|l|l|l|l|}
\hline Variable & Mean & Std. Dev. & Skewness & Kurtosis & JB Test \\
\hline Corp.Gov. Index & -0.019051 & 2.185858 & -0.350007 & 4.663083 & 80.71827 \\
\hline ISE100 Index & 0.013254 & 2.251584 & 0.081367 & 6.00650 & 224.7498 \\
\hline
\end{tabular}

The stationary of the series are determined by Augmented Dickey-Fuller and Phillips-Peron Unit Root Test using as the test equation where $Y$ represents daily logarithmic return of an index. Results in Table 2 show that CGI and ISE-100 Index are both stationary times series.

$$
\Delta Y_{t}=\alpha_{1} Y_{t-1}+\alpha_{i} \Delta Y_{t-i} \sum_{i=1}^{p} \Delta Y_{t-i}+e_{t}
$$

Table 2. Results of ADF and Phillips-Peron Unit Root Tests

\begin{tabular}{|l|l|l|l|l|l|}
\hline \multicolumn{4}{|l|}{ ADF Unit Root Test } & Phillips-Peron Unit Root Test \\
\hline Variable & Test Statistic & Prob. & Variable & Test Statistic & Prob. \\
\hline CGI & -21.71068 & 0.0000 & CGI & -21.70813 & 0.0000 \\
\hline ISE-100 & -22.30891 & 0.0000 & ISE-100 & -22.27198 & 0.0000 \\
\hline Critical values & $\% 1$ & -2.568861 & Critical Values & Critical values & \\
& $\% 5$ & -1.941357 & & & \\
& & & & \\
\hline
\end{tabular}

*Lag length is stated (0) based on Schwarz Info Criterion.

\section{Methodology}

ARFIMA-FIGARCH model is proper to use long-memory in stock returns under heteroscedasticity assumptions by allowing time series bootstrapping. A comparison of ARFIMA-FIGARCH with its ancestors can show its methodological strength in examination process of market efficiency. 
Table 3. Comparison of ARFIMA-FIGARCH Model with Its Ancestors

\begin{tabular}{|l|l|}
\hline Model & Property \\
\hline AR & Short Memory and Homoskedasticity \\
\hline GARCH & Short Memory and Heteroskedasticity \\
\hline ARFIMA & Long Memory and Homoskedasticity \\
\hline ARFIMA-FIGARCH & Long Memory and Heteroskedasticity \\
\hline
\end{tabular}

ARFIMA-FIGARCH model has an advantage over other GARCH models in that it enables us to estimate long-term memory persistence in both stock returns (mean) and uncertainty in returns (variance) simultaneously. It is useful to detect the long memory in the returns and provides an empirical measure of return uncertainty that accounts for long memory in the second conditional moment of the stock return process.

ARFIMA-FIGARCH model is suitable to estimate the long-term dependence in time series data. First component of the model, namely ARFIMA process, first appears in finance literature in the studies of Granger and Joyeux (1980) and Hosking (1981). The model, known as Autoregressive Fractionally Integrated Moving Average (ARFIMA), allows for increased flexibility in modeling low-frequency dynamics. ARFIMA model is written as follows (Nagayasu, 2003);

$$
\phi(L)(1-L)^{d} y_{t}=\Theta(L) \varepsilon_{t}
$$

where $\mathrm{d}$ is fractional integration parameter as a real number, $\mathrm{L}$ is lag operator and $\varepsilon$ t is white noise residual. Polynomial structures in Equation (1) lie outside the unit circle, satisfying the stationarity and invariability conditions. The fractional differencing lag operator $(1-\mathrm{L}) \mathrm{d}$ is defined by the binomial expansion as follows.

$$
(1-L)^{d}=1-d L+\frac{d(d-1)}{2 !} L^{2}-\frac{d(d-1)(d-2)}{3 !} L^{3}+\ldots
$$

ARFIMA process is nonstationary when $\mathrm{d} \geq 0.5$. For $0<\mathrm{d}<0.5$, ARFIMA process is said to exhibit long memory. The process exhibits short memory for $\mathrm{d}=0$ and intermediate memory for $\mathrm{d}<0$.

The second part of ARFIMA-FIGARCH model, namely FIGARCH process is constructed by Baillie et al. (1996). It is based on GARCH process and assumes heteroscedasticity in time-varying variance of data. We can derive FIGARCH model by following GARCH and IGARCH models. The GARCH $(\mathrm{p}, \mathrm{q})$ process can be modeled as an ARMA process by using lag operator as in Equation 3.

$$
\left.\left[1-\alpha_{(\mathrm{L})-} \beta(\mathrm{L})\right]^{2}=\omega_{+[1-} \beta(\mathrm{L})\right]\left(\varepsilon_{t}^{2} \sigma_{t}^{2}\right)
$$

When the $\left[1-\alpha(\mathrm{L})^{-} \beta(\mathrm{L})\right]$ function has a unit root and the sum of $\alpha$ and $\beta$ parameters is 1 , it 
gives Integrated GARCH (IGARCH) model is structured by Engle and Bollerslev (1986) and denoted in Equation 4 (Laurent and Peters, 2001).

$$
\phi_{(\mathrm{L})(1-\mathrm{L})} \varepsilon_{t}^{2}=\omega+[1-\beta(\mathrm{L})]\left(\varepsilon_{t}^{2} \sigma_{t}^{2}\right)
$$

As we model the IGARCH process as a conditional variance of the squared error terms, it can be written in GARCH formulation as shown in Equation 5.

$$
\sigma_{t}^{2}=\frac{\omega}{1-\beta(L)}+\left\{1-\phi(L)(1-L)[1-\beta(L)]^{-1} \varepsilon_{t-1}^{2}\right.
$$

If the fractional difference of return (yt) has a static process, we can say that yt is in the fractional integration. If $(1-\mathrm{L}) \mathrm{d}=\mathrm{yt}=\varepsilon_{t}$, and $\mathrm{d}$ equals to 0 , yt becomes static and its autocorrelations are zero. If $\mathrm{d}$ is 1 , on the other hand, yt has unit root with zero frequency. In case of $0<\mathrm{d}<1$, the autocorrelations of yt slowly reaches into zero. For that reason, the fractionally integrated models are seen as the models including long memory (Harris and Sollis, 2003; Cifter and Ozun, 2007). Baillie et al. (1996) establish Fractionally Integrated GARCH (FIGARCH) model by replacing the lag operator with (1-L)d in the IGARCH model. FIGARCH model is expressed in Equation 6.

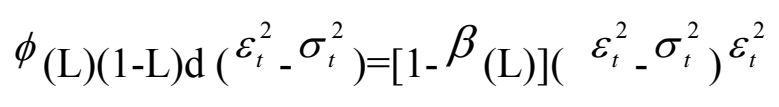

The conditional variance in the FIGARCH model is estimated by Equation 7.

$$
\left.\sigma_{t=}^{2} \omega_{[1-} \beta(\mathrm{L})\right]-1+\{1-[1-\beta(\mathrm{L})]-1 \quad \phi(\mathrm{L})(1-\mathrm{L}) \mathrm{d}\} \varepsilon_{t}^{2}
$$

In the Equation, $\omega *=[1-\beta(\mathrm{L})]-1, \lambda(\mathrm{L})=\left\{1-[1-\beta(\mathrm{L})]-1 \phi_{(\mathrm{L})(1-\mathrm{L}) \mathrm{d}\}} \varepsilon^{2}, 0<\mathrm{d}<1\right.$, and $\sigma_{t}^{2}=\omega *+\lambda(\mathrm{L})$

\section{Empirical Evidence}

We start to empirical analysis to determine proper ARMA parameters for the daily returns. Table 4 lists Schwarz Information Criterium (SIC) results for mean equations of the ISE-100 Index and CGI. The minimum SCI for ISE-100 Index and CGI is determined by ARMA $(0,0)$ and $\operatorname{ARMA}(0,1)$ models, respectively. 
Table 4. Schwarz Information Criteria for Mean Equations of ISE-100 Index and CGI

\begin{tabular}{|l|l|l|}
\hline & ISE-100 & CGI \\
\hline ARMA $(0,0)$ & 4.4702 & 4.4109 \\
\hline ARMA $(1,0)$ & 4.4748 & 4.4101 \\
\hline ARMA $(0,1)$ & 4.4729 & 4.4093 \\
\hline ARMA $(1,1)$ & 4.4851 & 4.4207 \\
\hline ARMA $(2,0)$ & 4.4865 & 4.4219 \\
\hline ARMA $(0,2)$ & 4.4834 & 4.4182 \\
\hline ARMA $(2,1)$ & 4.4969 & 4.4298 \\
\hline ARMA $(1,2)$ & 4.4953 & 4.4280 \\
\hline ARMA $(2,2)$ & 4.4834 & 4.4341 \\
\hline ARMA $(3,0)$ & 4.4974 & 4.4317 \\
\hline ARMA $(0,3)$ & 4.4921 & 4.4265 \\
\hline ARMA $(3,1)$ & 4.5048 & 4.4422 \\
\hline ARMA $(3,2)$ & 4.5070 & 4.4457 \\
\hline ARMA $(1,3)$ & 4.5039 & 4.4383 \\
\hline ARMA $(2,3)$ & 4.4915 & 4.4441 \\
\hline ARMA $(3,3)$ & 4.5151 & 4.4389 \\
\hline
\end{tabular}

We examine existence of long-memory in mean return and conditional variance for both indexes. In Table 5, it is shown that the CGI does not show long-term memory in mean returns, as $\mathrm{d}$ parameter is statistically insignificant.

Table 5. ARFIMA $(0, d, 1)$ GARCH $(1,1)$ Model Results for CGI

\begin{tabular}{|l|l|l|}
\hline & Coefficient & Prob. \\
\hline Constant (mean) & 0.120000 & 0.2210 \\
\hline$\hat{d}$ & 0.045618 & 0.3807 \\
\hline $\mathrm{MA}(1)$ & & \\
\hline Constant (variance) & 0.026140 & 0.6673 \\
\hline$\alpha$ & 0.077491 & 0.2057 \\
\hline$\beta$ & 0.904263 & 0.0144 \\
\hline df & & 0.0000 \\
\hline Q1(5) & 5.619110 & \\
\hline Q2(5) & 2.79005 & 0.0000 \\
\hline
\end{tabular}

*Q1denotes Q-Statistics on Standardized Residuals, Q2 denotes Q-Statistics on Squared Standardized Residuals df indicates student $t$ distribution parameter.

As FIGARCH model is unsolved for $\operatorname{ARMA}(0,1)$ process, we take $\operatorname{ARMA}(1,0)$ process that gives second minimum SCI into consideration. As it does not produce a solution, neither, the model is solved by ARMA $(0,0)$ process that has third minimum SCI. The test results are 
displayed in Table 6. On the other hand, there is a long-term memory in conditional variance as $\mathrm{d}$ parameter is statistically significant.

Table 6. ARMA $(0,0)$ FIGARCH $(1, d, 1)$ Model Results for CGI

\begin{tabular}{|l|l|l|}
\hline & Coefficient & prob. \\
\hline Constant (mean) & 0.127358 & 0.0892 \\
\hline Constant (variance) & 0.456778 & 0.1326 \\
\hline$\tilde{d}$ & 0.362769 & 0.0001 \\
\hline$\phi$ & -0.278223 & 0.2093 \\
\hline$\beta$ & & 0.7065 \\
\hline df & 0.085192 & \\
\hline Q1(5) & & 0.0000 \\
\hline Q2(5) & 6.255004 & 0.0633242 \\
\hline
\end{tabular}

*Q1denotes Q-Statistics on Standardized Residuals, Q2 denotes Q-Statistics on Squared Standardized Residuals df indicates student $t$ distribution parameter.

We try to investigate coexistence of long-term memory in mean returns and conditional variance, but for all model forms, we cannot reach any approximations. To examine existence of long-term memory in ISE-100 Index, firstly, ARFIMA-GARCH model parameters are estimated. As d parameters is not statistically significant, mean return does not have long-term memory. The test results are summarized in Table 7.

Table 7. ARFIMA $(0, d, 0)$ GARCH $(1,1)$ Model Results for ISE-100 Index

\begin{tabular}{|l|l|l|}
\hline & Coefficient & prob. \\
\hline Constant (mean) & 0.081368 & 0.4129 \\
\hline$\hat{d}$ & 0.042490 & 0.2322 \\
\hline Constant (variance) & 0.127552 & 0.1262 \\
\hline$\alpha$ & 0.079797 & 0.0042 \\
\hline$\beta$ & 0.895769 & 0.0000 \\
\hline df & & \\
\hline Q1(5) & 6.433340 & 0.0001 \\
\hline Q2(5) & 1.91008 & 0.8614415 \\
\hline
\end{tabular}

*Q1denotes Q-Statistics on Standardized Residuals, Q2 denotes Q-Statistics on Squared Standardized Residuals df indicates student t distribution parameter.

On the other hand, for ISE-100 Index, we find that conditional variance shows long-term memory. As Table 8 displays, d parameter is statistically significant in ARMA-FIGARCH model. 
Table 8. ARMA (0, 0) FIGARCH (1, d, 1) Model Results for ISE-100 Index

\begin{tabular}{|l|l|l|}
\hline & Coefficient & prob. \\
\hline Constant (mean) & 0.103914 & 0.1690 \\
\hline Constant (variance) & 0.345492 & 0.1717 \\
\hline$\tilde{d}$ & 0.386106 & 0.0011 \\
\hline$\phi$ & & 0.2214 \\
\hline$\beta$ & -0.200813 & 0.3419 \\
\hline df & & \\
\hline Q1(5) & 0.192536 & 0.0003 \\
\hline Q2(5) & & 0.1372585 \\
\hline
\end{tabular}

*Q1denotes Q-Statistics on Standardized Residuals, Q2 denotes Q-Statistics on Squared Standardized Residuals df indicates student $t$ distribution parameter.

Finally, we examine if there is coexistence of long-term memory in mean return and conditional variance exists for ISE-100 Index by employing ARFIMA-FIGARCH model. As Table 9 shows, $d$ parameter is statistically insignificant for mean returns while it does for conditional variance.

Table 9- ARFIMA (0, d, 0) FIGARCH $(1, d, 1)$ Model Result for ISE-100 Index

\begin{tabular}{|l|l|l|}
\hline & Coefficient & prob. \\
\hline Constant (mean) & 0.096209 & 0.3366 \\
\hline$\hat{d}$ & 0.043348 & 0.2156 \\
\hline Constant (variance) & 0.309039 & 0.1999 \\
\hline$\tilde{d}$ & 0.390428 & 0.0010 \\
\hline$\phi$ & -0.155441 & 0.3619 \\
\hline$\beta$ & 0.247381 & 0.2253 \\
\hline df & & \\
\hline Q1(5) & 6.673643 & 0.0003 \\
\hline Q2(5) & 3.51051 & 0.6217985 \\
\hline
\end{tabular}

*Q1denotes Q-Statistics on Standardized Residuals, Q2 denotes Q-Statistics on Squared Standardized Residuals df indicates student $t$ distribution parameter.

\section{Discussions and Concluding Remarks for Future Research}

Corporate governance rules are popularly attractive recently in Turkey, as a fast developing market. Istanbul Stock Exchange constructed an index called Corporate Governance Index 
including market values of companies having corporate governance rates. In this empirical research paper, for the first time in the literature, we examine long-memory effect in the Corporate Governance Index in Turkish equity markets by using ARFIMA-FIGARCH and ARFIMA-GARCH models. We produce test results for the benchmark index, namely, ISE-100 Index for Turkish equity markets for a comparison, as well.

Test results display the fact that both CGI and ISE-100 Index do not have long-term memory indicating that the equity markets have weak-form efficiency in Turkey. We try to investigate coexistence of long-term memory in mean returns and conditional variance, but we cannot reach any approximations for all model forms. However, as d parameter of conditional variance for CGI is found statistically significant by using ARMA-FIGARCH model, we can conclude that it follows long-term memory process. For ISE-100 Index, we witness long-term memory in conditional variance by employing ARMA-FIGARCH model. On the other hand, for both series, mean returns do not show long-term memory indicating that markets have informational efficiency in Turkey. In addition, coexistence of long-term memory in mean returns for CGI and ISE-100 Index is statistically insignificant. However, from the test results of ARFIMA-FIGARCH model, we can argue that coexistence of long-term memory in conditional variance exists for the series.

The empirical results can be interpreted that having corporate governance rate does not create any difference in informational efficiency. However, in practice, it should be remembered that in the market, companies with high market capitalization have corporate governance index. As these companies have a major percentage of total market capitalization, they have an importance in directions of market behaviours. Future research, preferably by employing qualitative research methods, as well, can examine the effects of corporate governance index on general market behaviours.

\section{References}

Baillie, RT., T. Bollerslev, and Mikkelsen, H.O. (1996). Fractionally Integrated Generalized Autoregressive Conditional Heteroskedasticity, Journal of Econometrics, 74:3-30

Bollerslev, T. (1986). Generalized Autoregressive Conditional Heteroskedasticity, Journal of Econometrics, 31:307-327.

Bollerslev, T., and Mikkelsen, H.O (1996). Modelling and pricing long memory in stock market volatility. Journal of Econometrics, 73:151-84

Cifter, A. and Ozun, A. (2007). The Predictive Performance of Asymmetric Normal Mixture GARCH in Risk Management: Evidence from Turkey, Bankacilik ve Finansal Piyasalar Dergisi, 1(1).:7-35

Cung, C.F. (1999). Estimating the Fractionally Integrated GARCH Model, National Taiwan University, Working Paper.

Davidson, J. (2001). Moment and Memory Properties of Linear Conditional Heteroskedasticity Models, Manuscript, Cardiff University 
Easterbrook, F.H. and Daniel R. F. (1981). The Proper Role of a Target's Management in Responding to a Tender Offer, Harvard Law Review, 94(6).: 1161-1204.

Engle R. F. (1982). Autoregressive Conditional Heteroscedasticity with Estimate of the Variance of United Kingdom Inflation, Econometrica, 50:987-1007

Engle, R. and Bollerslev, T. (1986). Modeling the Persistence of Conditional Variances. Econometric Reviews, 5:1-50.

Glosten, L.R., Jagahannathan, R., and Runkle, D. E. (1993). On the Relationship between the Expected Value and The Volatility of the Nominal Excess Return on Stocks, Journal of Finance, 48:1779-1801

Gompers, P. A., J. L. Ishii and A. Metrick (2003). Corporate Governance and Equity Prices, Quarterly Journal of Economics, 118 (1).: 107-155.

Granger, C. W. J. Testing for Causality: A Personal Viewpoint, J. Econ. Dynamics and Control 2(1980).:329-52.

Granger, Clive. W. J. and R. Joyeux, 1980 An Introduction to Long-Memory Time Series Models and Fractional Differencing," Journal of Time Series Analysis, 1(1).:15-29.

Harris, R. and Sollis, R. (2003). Applied Time Series Modelling and Forecasting, Wiley Press

Hermalin, B. and M. Weisbach (2003). Board of directors as an endogenously determined institution: A survey of the economic literature, Economic Policy Review 9: 7-26.

Hosking, J. R. M., (1981). Fractional Differencing, Biometrika, 1(1).: 165-76.

Hurst, H. (1951). Long-term storage capacity of reservoirs, Transactions of the American Society of Civil Engineers 116:770-808.

Johnson, S. A., T. Moorman and S. Sorescu (2005). Governance, Stock Return, and Market Efficiency, MPRA No. 6414

Karathanassis, G. A. and A. A. Drakos (2004). A Note on Equity Ownership and Corporate Value in Greece, Managerial and Decision Economics, 25:537-547.

Kasman, A. and Torun, E. (2007). Long Memory in the Turkish Stock Market Return and Volatility, Central Bank Review 2(2007).:13-27

Laurent, S. and Peters, J. (2002). G@rch 2.30: An Ox Package for Estimating and Forecasting Various ARCH Models, Université de Liège, Working Paper.

Mandelbrot, B. (1963). New methods in statistical economics, Journal of Political Economy, 71:421-440.

Nagayasu, J. (2003). The Efficiency of the Japanese Equity Market, IMF Working Papers, 03/142, International Monetary Fund.

Nelson, D.B. (1991). Conditional Heteroskedasticity in Asset Returns: A New Approach. Econometrica, 59(2):: 347-370 
Taylor, S. (1986). Modelling Financial Time Series. Wiley, New York

Tse, Y. (1998). The Conditional Heteroscedasticity of the Yen-Dollar Exchange Rate, Journal of Applied Econometrics, 193:49-55 